\title{
Pré-resfriamento sobre a qualidade de pêssegos 'Chiripá'
}

\author{
Pre-cooling on 'Chiripá' peaches quality
}

\author{
Auri Brackmann ${ }^{I^{*}}$ Anderson Weber ${ }^{\mathrm{I}}$ Ricardo Fabiano Hettwer Giehl ${ }^{\mathrm{II}}$ \\ Ana Cristina Eisermann"II
}

\section{RESUMO}

\begin{abstract}
O objetivo deste trabalho foi avaliar a qualidade física e química e a incidência de distúrbios fisiológicos em pêssegos 'Chiripá' submetidos a diferentes formas de préresfriamento. Os tratamentos avaliados foram: [1] resfriamento convencional em câmara frigorífica $\left(-0,5^{\circ} \mathrm{C}\right.$ e UR de $\left.95 \%\right)$; [2] resfriamento sob ar forçado $\left(-1,5^{\circ} \mathrm{C}\right)$ até a temperatura da polpa atingir $0^{\circ} \mathrm{C}$; [3] resfriamento em água a $1^{\circ} \mathrm{C}(R A)$ até $15^{\circ} \mathrm{C}$; [4] RA até $10^{\circ} \mathrm{C}$; [5] RA até $5^{\circ} \mathrm{C}$; [6] RA até $1^{\circ} \mathrm{C}$. Os frutos foram analisados após 35 dias a $-0,5^{\circ} \mathrm{C}$, mais dois e quatro dias a $20^{\circ} \mathrm{C}$. Verificou-se menor síntese de etileno nos frutos submetidos ao resfriamento lento e ao resfriamento com ar forçado, durante o período a $20^{\circ} \mathrm{C}$. Nesses frutos, a quantidade de suco livre foi significativamente menor após quatro dias a $20^{\circ} \mathrm{C}$, demonstrando uma aparente relação entre a reduzida síntese de etileno e a baixa suculência, o que é uma manifestação de lanosidade. Os frutos resfriados de forma lenta apresentaram firmeza da polpa mais elevada. Todas as formas de resfriamento com a água na temperatura de $1^{\circ} \mathrm{C}$ resultaram em maior porcentagem de frutos com manchas na epiderme, possivelmente em razão da baixa temperatura da água do pré-resfriador, indicando que o resfriamento em água não é recomendado para pêssegos 'Chiripá'.
\end{abstract}

Palavras-chave: Prunus persica, lanosidade, etileno, respiração, hidroresfriamento, resfriamento em ar forçado.

\section{ABSTRACT}

The aim of this research was to evaluate the physic and chemical quality and the incidence of physiological disorders in Chiripá peaches submitted to different precooling forms. The treatments evaluated, were: [1] slow cooling in the storage chamber $\left(-0.5^{\circ} \mathrm{C}\right.$ e UR de $\left.95 \%\right)$; [2] forced-air cooling $\left(-1.5^{\circ} \mathrm{C}\right)$ until the pulp reached $0^{\circ} \mathrm{C}$; [3] hydrocooling until the pulp reached $15^{\circ} \mathrm{C}$; [4] hydrocooling until $10^{\circ} \mathrm{C}$; [5] hydrocooling until $5^{\circ} \mathrm{C}$; [6] hydrocooling until $1^{\circ} \mathrm{C}$. The fruits were evaluated after 35 days at $-0.5^{\circ} \mathrm{C}$ and more two and four days at $20^{\circ} \mathrm{C}$. Lower ethylene synthesis during shelf-life at $20^{\circ} \mathrm{C}$ was verified in fruits submitted to both slow cooling and forcedair precooling. In those fruits, the succulence was significantly lower in the $4^{\text {th }}$ day at $20^{\circ} \mathrm{C}$, demonstrating an apparent relationship between the reduced ethylene synthesis and the largest wooliness incidence. Slow cooled fruits showed highest flesh firmness. All hydrocooling forms resulted in larger percentage of fruits with stains in the epidermis, possibly due to the low temperature of the precooler water. Therefore the precooling in water is not recommended for Chiripá peaches.

Key words: Prunus persica, mealiness, ethylene, respiration, hydrocooling, forced-air precooling.

\section{INTRODUÇÃO}

O Rio Grande do Sul é maior produtor brasileiro de pêssegos (AGRIANUAL, 2008). As cultivares Chiripá e Chimarrita são as de maior destaque para o consumo in natura, em razão de suas características de coloração, sabor e polpa branca. Pêssegos 'Chiripá' são colhidos tardiamente, o que justifica seu armazenamento como forma de prolongar o período de oferta desses frutos no mercado, especialmente quando os preços se elevam (AGRIANUAL, 2008).

Apesar dos benefícios do armazenamento refrigerado na conservação de pêssegos e nectarinas, grande parte das cultivares comerciais são sensíveis à

'Departamento de Fitotecnia, Centro de Ciências Rurais (CCR), Universidade Federal de Santa Maria (UFSM), 97105-900, Santa

Maria, RS, Brasil. E-mail: auribrackmann@gmail.com. *Autor para correspondência.

"Institut für Pflanzenernährung, Universität Hohenheim, Stuttgart, Alemanha. 
ocorrência de dano por frio, quando armazenadas por longos períodos (Von MOLLENDORFF et al., 1989; ZHOU et al., 2001), o que causa escurecimento da epiderme e lanosidade. Algumas cultivares de pêssego, como a 'Chiripá', são particularmente sensíveis à ocorrência de dano por frio, especialmente a lanosidade, que é um distúrbio fisiológico que causa a diminuição de suco livre na polpa do fruto (GIEHL et al., 2008). Acredita-se que esse distúrbio fisiológico se desenvolva durante o período de armazenamento sob baixas temperaturas, sendo causado pelo metabolismo anormal das paredes celulares dos frutos (BRUMMEL et al., 2004).

O rápido resfriamento, após a colheita, tem se mostrado eficiente para o prolongamento da vida pós-colheita de frutas e hortaliças, especialmente para frutos altamente perecíveis, como o pêssego. PRANGE (1994) afirma que o abaixamento da temperatura diminui a respiração dos frutos, o que, segundo BARTLEY (1986), retarda o amadurecimento.

O pré-resfriamento consiste na rápida retirada do calor de campo do fruto recém-colhido antes do transporte, armazenamento ou processamento. O pré-resfriamento pode ser realizado por diferentes formas, como, por exemplo, o resfriamento por ar forçado, o hidroresfriamento, o resfriamento com uso de gelo e o resfriamento a vácuo, sendo que cada forma difere na eficiência da remoção de calor, no custo de utilização e na eficiência da manutenção da qualidade física e química para cada tipo de fruto (KALBASIASHTARI, 2004). Esse mesmo autor afirma ainda que as técnicas para remover o calor de campo de frutas e hortaliças recém-colhidas podem reduzir a atividade microbiana, as taxas respiratórias, a senescência de frutos, assim como a produção de etileno. O préresfriamento diminui o amadurecimento, diminui a perda de massa e pode diminuir a incidência de podridões, portanto auxiliando no prolongamento da vida póscolheita dos frutos (FERREIRA et al., 1994; REINA et al., 1995). Conforme FACHINELLO (2008), os métodos mais utilizados de pré-resfriamento para pêssegos são o resfriamento na própria câmara de armazenamento, um sistema lento que pode afetar a qualidade do pêssego, e o hidroresfriamento, que é um sistema mais rápido que o anterior. O hidroresfriamento, no entanto, quando aplicado a frutos oriundos de pomares com problemas fitossanitários, pode aumentar a ocorrência de podridões, enquanto que o resfriamento por ar frio forçado, apesar de eficiente, pode levar à desidratação da fruta.

A recomendação para pêssegos e ameixas é a utilização do pré-resfriamento, tanto em água, como em ar (STREIF, 1995). Em pêssegos, SCOTT et al. (1969) não observaram melhoria no controle da degenerescência interna com o pré-resfriamento em água. Porém, BRACKMANN et al. (2000) observaram que o resfriamento em água proporciona maior firmeza de polpa dos frutos quando comparado com o resfriamento em ar forçado para a cultivar Chiripá, avaliado na abertura da câmara. Contudo, esse resultado não se manteve após dois dias a $20^{\circ} \mathrm{C}$, ocorrendo maior incidência de podridões em comparação ao resfriamento em ar. KALBASIASHTARI (2004) verificou que o método de hidroresfriamento foi eficiente na manutenção da firmeza de polpa em pêssegos e nectarinas. Além disso, esse mesmo autor afirma que o uso de ar forçado, apesar de representar uma boa alternativa, pode resultar em perda de massa dos frutos, especialmente se expostos a uma alta velocidade do ar.

O objetivo deste trabalho foi avaliar os efeitos de diferentes formas de pré-resfriamento sobre a qualidade física e química e a incidência de distúrbios fisiológicos em pêssegos 'Chiripá'.

\section{MATERIAL E MÉTODOS}

O experimento foi conduzido no Núcleo de Pesquisa em Pós-colheita (NPP) do Departamento de Fitotecnia da Universidade Federal de Santa Maria, com frutos da cultivar 'Chiripá' provenientes de pomares comerciais localizados no Município de Farroupilha, Rio Grande do Sul. Imediatamente após a chegada dos frutos, foi realizada a seleção destes, eliminando aqueles com lesões e baixo calibre, e a homogeneização das amostras experimentais.

O delineamento experimental utilizado foi o de blocos ao acaso (DBC), com quatro repetições, sendo a unidade experimental composta por 20 frutos. Após a aplicação dos tratamentos, os pessêgos foram armazenados em minicâmaras experimentais com volume de $0,232 \mathrm{~m}^{3}$, acondicionadas em câmaras frigoríficas com volume de $45 \mathrm{~m}^{3}$.

Os tratamentos avaliados foram diferentes métodos de pré-resfriamento dos frutos, sendo [1] resfriamento convencional em câmara frigorífica $\left(-0,5^{\circ} \mathrm{C}\right.$ e UR de $95 \%)$; [2] resfriamento sob ar forçado $\left(-1,5^{\circ} \mathrm{C}\right)$ até a temperatura da polpa atingir $0^{\circ} \mathrm{C}$; [3] resfriamento em água a $1^{\circ} \mathrm{C}(\mathrm{RA})$ até $15^{\circ} \mathrm{C}$, [4] RA até $10^{\circ} \mathrm{C}$, [5] RA até $5^{\circ} \mathrm{C}$, [6] RA até $1^{\circ} \mathrm{C}$. A temperatura da água foi de $1^{\circ} \mathrm{C}$ para todos os frutos pré-resfriados em água, independentemente da temperatura final de préresfriamento. Os pessêgos foram armazenados em atmosfera refrigerada na temperatura de $-0,5^{\circ} \mathrm{C}$ e umidade relativa de $95 \%$ durante 35 dias. 
$\mathrm{O} \mathrm{CO}_{2}$ resultante do processo respiratório foi eliminado com o uso de cal hidratada colocada no interior da minicâmara. A temperatura das câmaras foi diariamente monitorada com auxílio de termômetros de alta precisão inseridos na polpa de um fruto, permitindo variação de temperatura de $0,1^{\circ} \mathrm{C}$, para mais ou para menos.

As análises de qualidade dos frutos foram realizadas após 35 dias de armazenamento seguidos de mais dois e quatro dias de exposição a $20^{\circ} \mathrm{C}$ e umidade relativa de $90 \%$, para simular o período de comercialização. Foram analisados os seguintes parâmetros: acidez titulável determinada pela titulação com $\mathrm{NaOH}$ 0,1N de uma solução contendo $10 \mathrm{~mL}$ de suco diluídos em 100mL de água destilada, até atingir $\mathrm{pH} 8,1$. Os valores foram expressos em meq $100 \mathrm{~mL}^{-1}$. A porcentagem de frutos manchados foi determinada pela contagem dos frutos com a epiderme escurecida, sendo expressa em porcentagem. A firmeza da polpa foi avaliada na região equatorial dos frutos, em dois lados opostos sem a presença de epiderme. Para a determinação, utilizou-se um penetrômetro manual (Effigi ${ }^{\circledR}$, Itália), com ponteira de 7,9mm de diâmetro, sendo os valores expressos em Newton (N). A porcentagem de suco livre foi determinada de acordo com metodologia proposta por CRISOSTO \& LABAVITCH (2002), com pequenas alterações. Aproximadamente $40 \mathrm{~g}$ de polpa por amostra foram prensados numa prensa experimental desenvolvida no próprio NPP/UFSM. Essa alíquota foi submetida a uma pressão de cerca de $10 \mathrm{~kg} \mathrm{~cm}^{-2}$ durante um min. O suco extraído pela prensagem foi, então, centrifugado a $10.000 \mathrm{~g}$ durante $10 \mathrm{~min}$. Em seguida, o suco obtido foi separado do sobrenadante e filtrado. A partir da diferença entre a massa inicial da polpa $(\approx 40 \mathrm{~g})$ e o peso final do suco, foi obtida a porcentagem de suco livre na polpa. A produção de etileno foi determinada com a utilização de aproximadamente $1400 \mathrm{~g}$ de frutos, colocados em recipientes com volume de $5000 \mathrm{~mL}$. Estes foram fechados hermeticamente durante aproximadamente uma hora. Para a análise da produção de etileno, foram injetadas duas amostras de gás de $1 \mathrm{~mL}$, provenientes de cada recipiente, em um cromatógrafo a gás, marca Varian, equipado com um detector de ionização por chama (FID) e coluna Porapak N80/100. Calculou-se a síntese de etileno em $\mu \mathrm{L} \mathrm{C}_{2} \mathrm{H}_{4}$ $\mathrm{kg}^{-1} \mathrm{~h}^{-1}$ por meio da concentração de etileno, da massa do fruto, do volume do espaço livre no recipiente e do tempo de fechamento. A respiração foi determinada pela quantificação da produção de $\mathrm{CO}_{2}$. $\mathrm{O}$ ar do mesmo recipiente utilizado para a determinação do etileno foi circulado por meio de um analisador eletrônico de $\mathrm{CO}_{2}$, marca Agri-datalog ${ }^{\circledR}$. A partir da concentração de $\mathrm{CO}_{2}$, do espaço livre do recipiente, do peso do fruto e do tempo de fechamento, foi calculada a respiração em $\mathrm{mL}$ $\mathrm{CO}_{2} \mathrm{~kg}^{-1} \mathrm{~h}^{-1}$.

Para cada parâmetro avaliado, foi efetuada a análise de variância, sendo as médias comparadas pelo teste de Duncan, a 5\% de probabilidade de erro. As variáveis expressas em porcentagem foram transformadas pela fórmula arco seno $\sqrt{\mathrm{x} / 100}$, antes da análise de variância (ANOVA).

\section{RESULTADOS E DISCUSSÃO}

O tempo necessário para o pré-resfriamento de pêssegos 'Chiripá', até a polpa atingir $1^{\circ} \mathrm{C}$, foi diferente nos métodos testados (Figura 1). O préresfriamento em água foi o método que mais rapidamente reduziu a temperatura da polpa dos frutos até $1^{\circ} \mathrm{C}$, sendo essa temperatura atingida em uma hora e 25 minutos. Para o método de ar forçado, na velocidade de $16 \mathrm{~km} \mathrm{~h}^{-1}$ $\left(5,0 \mathrm{~m} \mathrm{~s}^{-1}\right)$ e $-1,5^{\circ} \mathrm{C}$, o abaixamento da temperatura ocorreu em duas horas e 45 minutos, enquanto que o resfriamento convencional, na câmara frigorífica, demorou aproximadamente 12 horas (Figura 1). Conforme GOLOB et al. (2002), o pré-resfriamento em água é mais rápido e mais homogêneo que o préresfriamento em ar forçado. O pré-resfriamento é importante para reduzir rapidamente o calor de campo dos frutos, uma vez que quanto mais rapidamente a temperatura dos frutos é reduzida, menor é a probabilidade de haver perdas pós-colheita, devido a mudanças metabólicas (BROSNAN \& SUN, 2001). Segundo KALBASI-ASHTARI (2004), a taxa de deterioração de frutos aumenta de forma logarítmica com o aumento da temperatura.

A diminuição da temperatura dos frutos no resfriamento em água ocorre em maior velocidade em temperaturas mais altas, apresentando um comportamento exponencial de redução da temperatura (Figura 1). Segundo ELANSARI (2008), o tempo necessário para reduzir a temperatura até sete-oitavos é independente da temperatura inicial do produto. Dessa forma, conforme BROSNAN \& SUN (2001), se em duas horas a temperatura é reduzida em $50 \%$ da temperatura inicial, em mais duas horas a temperatura será reduzida até $25 \%$ e assim sucessivamente, formando, portanto, uma curva exponencial de redução da temperatura, como a observada no presente trabalho (Figura 1).

A firmeza da polpa se manteve mais alta aos dois dias a $20^{\circ} \mathrm{C}$ nos frutos resfriados na câmara de armazenagem ou naqueles pré-resfriados rapidamente em ar forçado, não diferindo do pré-resfriamento em água até a temperatura de $15^{\circ} \mathrm{C}$ (Figura 2A). Esses 

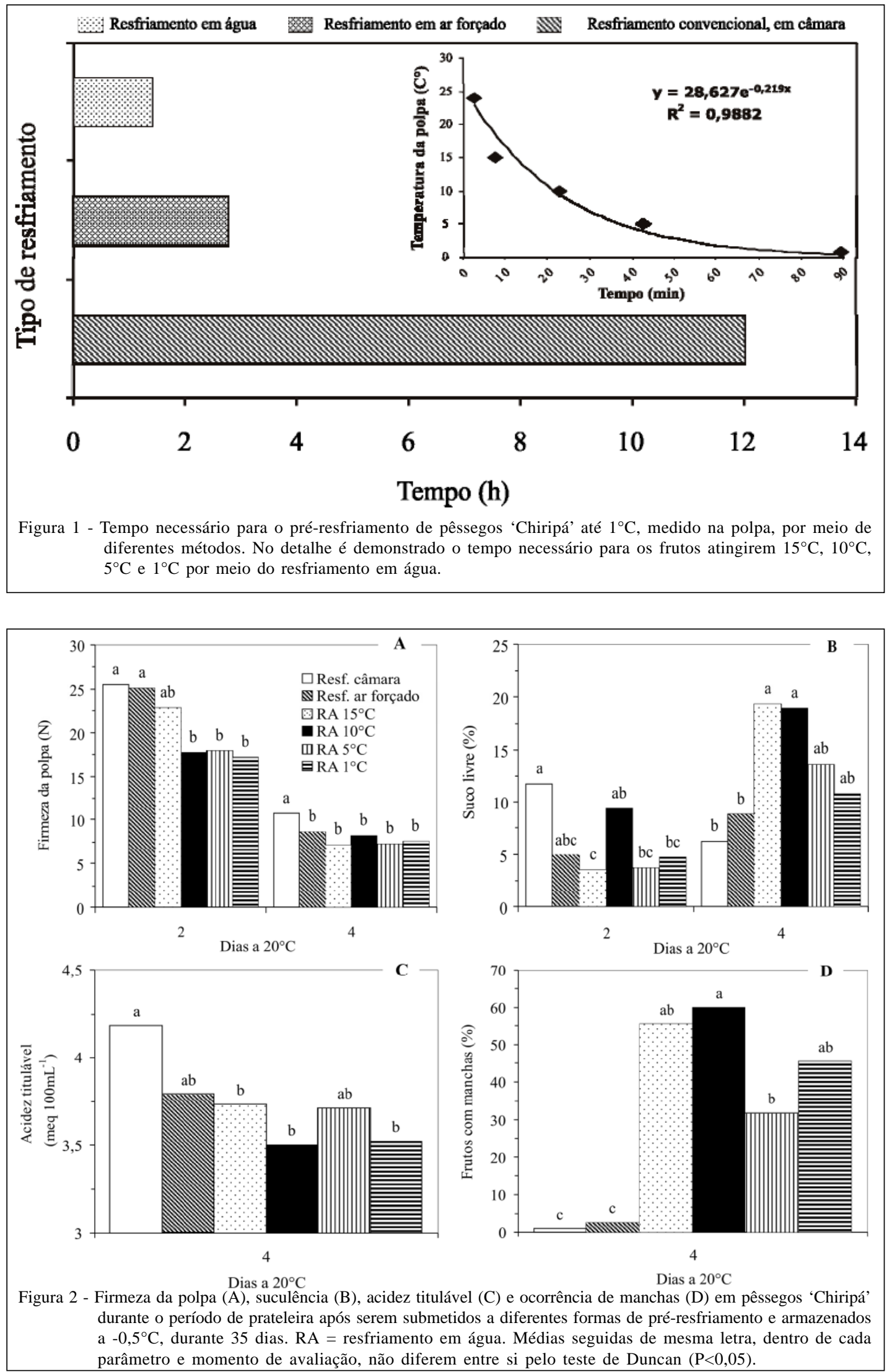

Ciência Rural, v.39, n.8, nov, 2009. 
resultados contrariam os obtidos por KLUCH et al. (2003), que obtiveram maiores valores de firmeza em pêssegos ‘Chiripá’ pré-resfriados em água em relação aos resfriados em ar forçado após o armazenamento em atmosfera refrigerada por 30 dias. Após quatro dias a $20^{\circ} \mathrm{C}$, todos os frutos que sofreram pré-resfriamento apresentaram menores valores de firmeza de polpa do que os frutos resfriados lentamente (Figura 2A).

Os pêssegos pré-resfriados em água até $10^{\circ} \mathrm{C}$ e os resfriados na câmara de armazenagem apresentaram as maiores porcentagens de suco livre após dois dias a $20^{\circ} \mathrm{C}$, apresentando a menor ocorrência de lanosidade (Figura 2B). Já após quatro dias, os frutos pré-resfriados em água mantiveram as maiores porcentagens de suco livre (Figura 2B). Esses resultados podem estar relacionados à rápida diminuição da temperatura de campo dos frutos resfriados em água, diminuindo a ação da enzima pectinaesterase e evitando a formação de pectinas de alto peso molecular, que reduzem a suculência (BRUMMEL et al., 2004). Já KLUCK et al. (2003), utilizando um método subjetivo, com atribuição de índices, para a análise da suculência, não verificaram diferença entre as diferentes formas de préresfriamento na incidência de lanosidade em pêssegos.

A acidez titulável foi menor em todos os frutos pré-resfriados em água ou por ar forçado. No entanto, os frutos pré-resfriados em ar forçado ou em água até a temperatura de $5^{\circ} \mathrm{C}$ não diferiram daqueles resfriados na câmara de armazenagem, que apresentaram maior acidez titulável (Figura 2C). O préresfriamento em água resultou em elevada incidência de manchas na epiderme (Figura 2D). Provavelmente, a exposição dos frutos a água fria diminui o volume de ar interno dos frutos em consequência do resfriamento, provocando pequena absorção de água fria pelo fruto. Essa absorção, possivelmente, é a causa do dano na epiderme do fruto, e esse estresse causa um aumento na produção de etileno (Figura 3A). GIEHL et al. (2008) verificaram que, quando pêssegos 'Chiripá' apresentaram maior atividade da ACC oxidase e produziram maior quantidade de etileno, os frutos apresentaram maior teor de suco livre. Esses resultados também foram observados neste trabalho, sendo que os frutos pré-resfriados em água apresentaram maior pico de produção de etileno (Figura 3A) e maior porcentagem de suco livre após quatro dias a $20^{\circ} \mathrm{C}$ (Figura 2B). Além disso, o etileno estimula a atividade de peroxidases (HYODO et al., 1991) e polifenoloxidases (COUTURE et al., 1993), que, por sua vez, oxidam os compostos fenólicos extravasados devido aos danos na epiderme, resultando no escurecimento (SALVIET \& MORRIS, 1990). No terceiro dia de exposição a $20^{\circ} \mathrm{C}$, os frutos apresentaram um pico de produção de etileno (Figura 3A).

Os frutos resfriados lentamente na câmara de armazenamento apresentaram maior taxa respiratória após um dia de exposição a $20^{\circ} \mathrm{C}$, não diferindo dos frutos pré-resfriados em água até $1^{\circ} \mathrm{C}$ (Figura 3B). Os frutos pré-resfriados em ar forçado exibiram baixa atividade respiratória durante os quatro dias de exposição a $20^{\circ} \mathrm{C}$. Entretanto, os frutos pré-resfriados em água apresentaram maior taxa respiratória ao final de quatro dias a $20^{\circ} \mathrm{C}$ (Figura 3B). Os resultados indicam a susceptibilidade dos pêssegos 'Chiripá' ao pré-resfriamento em água, pois esta pode causar maior

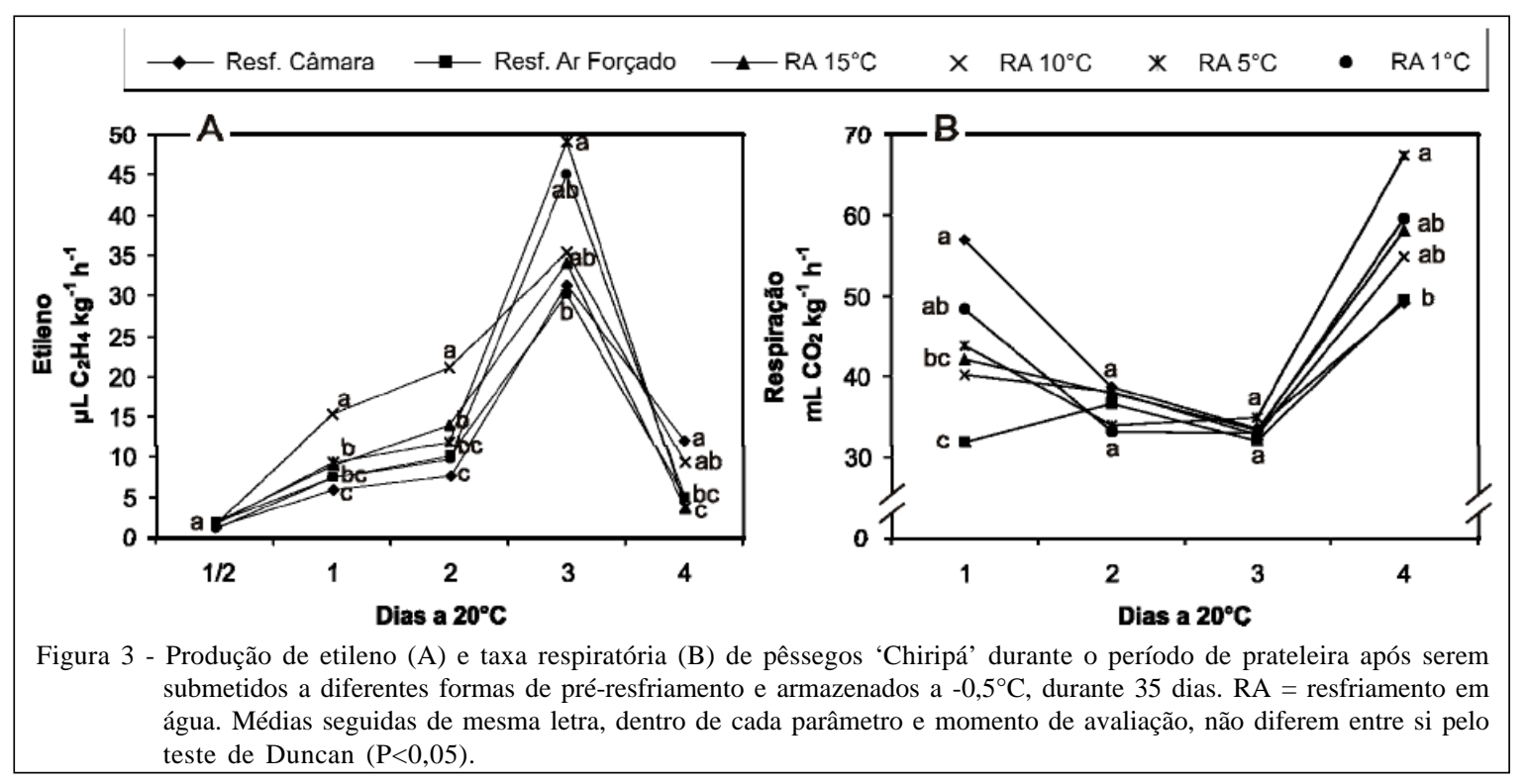

Ciência Rural, v.39, n.8, nov, 2009. 
incidência de danos na epiderme e assim resultar em maior taxa respiratória, uma vez que a taxa de deterioração durante a pós-colheita e a respiração estão intimamente relacionadas (FARRAGHER et al., 1984). A manutenção de reduzida taxa respiratória é essencial para garantir qualidade durante a comercialização do produto (BROSNAN \& SUN, 2001), sendo evitadas perdas demasiadas nesse período.

\section{CONCLUSÕES}

Todas as intensidades de pré-resfriamento em água resultaram em maior porcentagem de frutos com manchas na epiderme e maior produção de etileno, o que proporciona frutos com maior teor de suco livre. O pré-resfriamento em ar forçado é o método mais indicado para pêssegos 'Chiripá', apesar de nenhuma das condições de pré-resfriamento avaliadas proporcionar um controle satisfatório da lanosidade após 35 dias de armazenamento a $-0,5^{\circ} \mathrm{C}$.

\section{AGRADECIMENTOS}

Ao Conselho Nacional de Desenvolvimento Científico e Tecnológico (CNPq), pelas bolsas concedidas aos autores A. Weber (Bolsa de Mestrado) e A. Brackmann (Bolsa de Produtividade em Pesquisa); e à Coordenação de Aperfeiçoamento de Pessoal de Nível Superior (CAPES/DAAD), pela concessão de bolsa de doutorado ao autor R.F.H. Giehl.

\section{RFERÊNCIAS}

Agrianual. Anuário da Agricultura Brasileira. São Paulo: FNP, 2008. 516p.

BARTLEY, I.M. Changes in sterol and phospholipids composition of apples during storage at low temperature and low oxygen concentration. Journal Science of the Food and Agriculture, Maidstone, v.37, n.1, p.31-36, 1986. Disponível em: <http://www3.interscience.wiley.com/journal/ 113321690/abstract?CRETRY $=1 \&$ SRETRY $=0>$. Acesso em: 19 jun. 2009. doi: 10.1002/jsfa.2740370105

BROSNAN, T.; SUN, D-W. Precooling techniques and applications for horticultural products - a review. International Journal of Refrigeration, Oxford, v.24, p.154-170, 2001. Disponível em: <http://www.sciencedirect.com/ science? ob=ArticleURL\&_udi=B6V4R-428115S$5 \&$ \&user $=687358 \& \_$rdoc $=18 \_f m t=$ \&_orig $=$ search \&_sort $=d \&$ vie $\mathrm{w}=\mathrm{c} \&$ _acct $=\mathrm{C} 000037899 \&$ \& version $=1 \&$ \&urlVersion $=0$ \&_userid=687358\&md5=a717aec2b6f8a61e198aa1a211fb7229>. Acesso em: 19 jun. 2009. doi: 10.1016/S0140-7007(00)00017-7

BRACKMANN, A. et al. Pré-resfriamento e tratamento póscolheita de pêssegos cv. Chiripá frigoconservados. Revista Brasileira de Agrociência, Pelotas, v.6, n.1, p.27-29, 2000. Disponível em: <http://www.ufpel.tche.br/faem/agrociencia/ v6n1/artigo06.pdf>. Acesso em: 19 jun. 2009.

CRISOSTO, C.H.; LABAVITCH, J.M. Developing a quantitative method to evaluate peach (Prunus persica) flesh mealiness.
Postharvest Biology and Technology, Amsterdam, v.25, n.2, p.151-158, 2002. Disponível em: <http://www.sciencedirect.com/ science?_ob=MImg\&_imagekey=B6TBJ-44J6J29-1 F\&_cdi $=5144 \&$ \& user $=687358 \&$ \& orig = browse \& _ c o ve r D a te $=06 \% 2$ F $30 \% 2$ F 2002 \& _ s $\mathrm{k}=999749997 \& \mathrm{vi}$ e w $=\mathrm{c} \& \mathrm{wchp}=\mathrm{d} \mathrm{G} \mathrm{L} \mathrm{b} \mathrm{V} \mathrm{lz} \mathrm{-}$ zSkWz\&md5=36188851e618e92e48f47de497c62ad1\&ie=/ sdarticle.pdf $>$. Acesso em: 19 jun. 2009. doi: 10.1016/S09255214(01)00183-1.

COUTURE, R. et al. Physiological attributes related to quality attributes and storage life of minimally processed lettuce. Hortscience, Alexandria, v.28, p.723-725, 1993.

ELANSARI, A.M. Hydrocooling rates of Barhee dates at the Khalal stage. Postharvest Biology and Technology, Amsterdam, v.48, p.402-407, 2008. Disponível em: <http:// www.sciencedirect.com/science?_ob=MImg\&_imagekey=B6TBJ4S02D6G-1-C\&_cdi $=5144 \&$ \&user $=687358 \&$ _orig $=$ browse \&_c o ver D a te $=06 \% 2$ F $30 \% 2$ F 2008 \&_s k $=999519996 \&$ vi e w $=c \& w c h p=d G L z V l z-$ zSkzS\&md5=e6c9942128c76488782d45543a6fce4d\&ie =/ sdarticle.pdf $>$. Acesso em: 19 jun. 2009. doi: 10.1016/ j.postharvbio.2007.11.003.

FACHINELLO, J.C. Colheita, armazenamento refrigerado e qualidade da fruta. Acessado em 10 out. 2008. Online. Disponível em: http://www.ufpel.tche.br/pif/12.htm.

FARRAGHER, J.D. et al. Changes in parameters of cell senescence in carnation flowers after cold storage. Scientia Horticulturea, Amsterdam, v.22, p. 295-302, 1984.

FERREIRA, M.D. et al. Physiological responses of strawberry to film wrapping and precooling methods. Proceedings of the Florida State Horticultural Society, Florida, v.107, p.265-269, 1994. Disponível em: <http://fulltextt10.fcla.edu/ DLData/HP/HP $00000107 /$ S N $00971219 / 107$ 0/265269\%20(FERREIRA).pdf>. Acesso em: 19 jun. 2009.

GIEHL, R.F.H. et al. CA affects juiciness in peaches due to an earlier post-storage ethylene production. Acta Horticulturae, Wageningen, v.796, p.185-190, 2008.

GOLOB, P. et al. Crop post-harvest: science and technology. Principles and practices. London: Blackwell Science, 2002. V.1, 554p.

HYODO, H. et al. Wound-induced ethylene synthesis and its involvement in enzyme induction mesocarp tissue of Cucurbita maxima. Postharvest Biology and Technology, Amsterdam, v.1, n.2, p.127-136, 1991. Disponível em: <http:// www.sciencedirect.com/science?_ob=ArticleURL\&_udi=B6TBJ49 NX53W-4\&_user $=687358 \&$ \&_coverDate $=12 \% 2$ F 31 $\% 2 \mathrm{~F} 1991 \& \_$rdoc $=4 \& \_\mathrm{fmt}=$ high\&_orig $=$ browse \& $\_$srch $=$doc info(\%23toc\%235144\%231991\%23999989997\%23461966\%23FLP \%23display\%23Volume)\&_cdi=5144\&_sort=d\&_docanchor=\&_ct=11\&_acct= C $000037899 \&$ \&ersion $=1 \&$ \&urlVersion $=0 \&$ \&user $\mathrm{id}=687358 \& \mathrm{md} 5=860 \mathrm{c} 548 \mathrm{~b} 9 \mathrm{ff} 137878 \mathrm{c} 260 \mathrm{e} 647412863 \mathrm{c}>$. Acesso em: 19 jun. 2009. doi: 10.1016/0925-5214(91)90004-U

KALBASI-ASHTARI, A. Effects of post-harvest pre-cooling processes and cyclical heat treatment on the physico-chemical properties of "Red Haven Peaches" and "Shahmavch Pears" 
during cold storage. Agricultural Engineering International: the CIGR Journal of Scientific Research and Development, Florida, v.6, July, 2004. Disponível em: $<$ http://www.cigrjournal.org/index.php/Ejounral/article/view/ 524/518>. Acesso em: 19 jun. 2009.

KLUCH, H.D.W. et al. Efeito do pré-resfriamento e condições de armazenamento sobre a qualidade físico-química e lanosidade de pêssegos Cv. 'Chiripá'. Revista Brasileira de Agrociência, Pelotas, v.9, n.3, p.269-272, 2003. Disponível em: http:// www.ufpel.tche.br/faem/agrociencia/v9n3/artigo15.pdf. Acesso em: 19 jun. 2009.

PRANGE, R.K. Postharvest cooling of horticultural crops. Production technology report. Kentville, NS: Agriculture and Agri-Food Canada, Research Station, 1994. B4N1J5.

REINA, L.D. et al. Microbial control of cucumber hydrocooling water with Chlorine Dioxide. Journal of Food Protection, Iowa, v.58, n.5, p.541-546, 1995.

SALVIET, M.E.; MORRIS, L.L. Overview on chilling injury of horticultural products, in chilling injury of horticultural products. Boca Raton, FL: CRC, 1990. p.415.

SCOTT, K.J. et al. Low temperature injury of starking Delicious peaches in relation to weight lost during cool storage. Australian Journal of Experimental Agriculture and Animal Husbandry, Collingwood, v.9, p.364-366, 1969.

STREIF, J. Lagerung von stein und beerenobst. Besseres Obst, Insbruck, v.4, p.18-19, 1995.

Von MOLLENDORFF, L.J. et al. Effect of time of examination and ripening temperature on the degree of woolliness in nectarines. Journal of Horticultural Science, v.64, n.4, p.443-447, 1989.

ZHOU, H.-W. et al. The role of ethylene in the prevention of chilling injury in nectarines. Journal of Plant Physiology, Irvine, v.158, p.55-61, 2001. Disponível em: <http://www.sciencedirect.com/ science? ob=ArticleURL \& udi=B7GJ7-4DPXDXJ7\&_user=687358\&_rdoc=18_fmt=\&_orig=search\&_sort=d\&view=c\&_acc $\mathrm{t}=\mathrm{C} 000037899 \& \quad$ version $=1 \&$ url Version $=0$ \&_userid=687358\&md5=ea8e2bfa4c37322374b33e25ae9fff40>. Acesso em: 19 jun. 2009. doi: 10.1078/0176-1617-00126. 